\title{
The multiple faces of Langerhans cell histiocytosis in childhood: A gentle reminder
}

\author{
MARIA PAPADOPOULOU ${ }^{1}$, PARASKEVI PANAGOPOULOU ${ }^{1}$, \\ ANASTASIA PAPADOPOULOU ${ }^{1}$, EMMANUEL HATZIPANTELIS ${ }^{2}$, IOANNIS EFSTRATIOU ${ }^{3}$, \\ ASSIMINA GALLI-TSINOPOULOU ${ }^{1}$ and EFIMIA PAPADOPOULOU-ALATAKI ${ }^{1}$ \\ ${ }^{1}$ Fourth Department of Pediatrics, Aristotle University of Thessaloniki, Papageorgiou General Hospital; \\ ${ }^{2}$ Second Department of Pediatrics, Aristotle University of Thessaloniki, AHEPA General Hospital; \\ ${ }^{3}$ Pathology Department, Papageorgiou General Hospital, 56403 Thessaloniki, Greece
}

Received September 2, 2017; Accepted December 13, 2017

DOI: $10.3892 /$ mco.2017.1539

\begin{abstract}
Langerhans cell histiocytosis (LCH) is a rare hematologic disorder that results from the clonal multiplication and accumulation of immature dendritic Langerhans cells. Its reported incidence rate varies, but is considered to be 2.6-8.9 per million children who are $<15$ years of age each year. It may affect any system or organ. The present study reported 4 pediatric LCH cases in order to highlight the heterogeneity of the initial presentation, and the pitfalls that may mislead clinicians and delay diagnosis. The clinical features, as well as the pathognomonic imaging, pathology findings and treatment options were presented. LCH may be rare, but it should always be included in the differential diagnosis of persistent eczema, unexplained skin lesions, diabetes insipidus and persistent bone pain, among others. While the debate on pathogenesis and treatment is ongoing, high index of suspicion among pediatricians, pediatric oncologists and other specialists (pathologists, dermatologists, orthopaedic surgeons, general practitioners or family physicians) is essential for early diagnosis, and optimal outcome.
\end{abstract}

\section{Introduction}

Langerhans cell histiocytosis (LCH) is a rare hematological disorder caused by the clonal proliferation and accumulation of LCH cells, which have similar phenotypic features and are thought to be a myeloid-derived precursor of epidermal Langerhans cells (1). Its exact aetiology remains unknown but recent data show that in a significant percentage of $\mathrm{LCH}$ patients mutations that activate the RAS-RAF-MEK-ERK

Correspondence to: Professor Efimia Papadopoulou-Alataki, Fourth Department of Pediatrics, Aristotle University of Thessaloniki, Papageorgiou General Hospital, Ring Road, Nea Efkarpia, 56403 Thessaloniki, Greece

E-mail: efiala@otenet.gr

Key words: Langerhans cell histiocytosis, children, diabetes insipidus, rash, bone pain, lytic lesion pathway are identified [BRAF oncogene (V600E): 50-60\%, MAP2KI genes: $10-20 \%$, other genes (ERBB3 and ARAF)] (2). The disease has an extreme variety of possible clinical presentations ranging from a single focal bone lesion to a life-threatening multisystem disease requiring emergency and aggressive chemotherapy (3). LCH is a rare condition affecting $<1$ in 200,000 children younger than 15 years of age. Its incidence ranges from 2 to 9 cases per million per year, with a male to female ratio close to one. It can present at any age but among children its peak age at presentation is 3-4 years. There seems to be a seasonal variation with spikes in fall and winter (4). Whether this rare disorder is a neoplasia or a cancer-like condition of the immune system is still hotly debated and international collaborative trials aiming to identify the optimal treatment duration for the prevention of recurrent and the treatment of resistant disease are ongoing.

Herein, we report a striking series of four patients diagnosed with LCH in a single Pediatric Department with a catchment area of approximately 270,000 inhabitants during an eight-month period. We aim to highlight the heterogeneity of disease's presentation, to present the management and treatment options and to raise the index of suspicion for health care practitioners.

\section{Case report}

Four patients that were diagnosed with LCH in the Pediatric Department of a University Affiliated Hospital between September 2014 and April 2015 are presented after retrospective review of all patients' notes. Informed consent was obtained by all the parents of our patients. The present study was approved by the Papageorgiou Hospital Ethic Committee. Their demographic characteristics and initial clinical signs and symptoms are summarized in Table I.

\section{Clinical presentation}

Patient no. 1. A 5-month old female infant was admitted for erythema and edema of the left orbit, after a reported insect bite that had been treated with oral amoxicillin for seven days without improvement. Her family and medical histories were unremarkable, except for a persistent rash on the trunk 
Table I. Demographic characteristics, clinical and radiological findings as well as treatment stratification group of all patients.

\begin{tabular}{|c|c|c|c|c|}
\hline Patient & No. 1 & No. 2 & No. 3 & No. 4 \\
\hline Age & 5 months & 7 years & 4 months & $41 / 2$ years \\
\hline Gender & Female & Male & Female & Male \\
\hline Location & Left frontal bone, Skin & Left iliac bone & Perianal area & Brain, Left femur \\
\hline Clinical manifestation & $\begin{array}{l}\text { Oedema and redness, refractory } \\
\text { eczema, early teething }\end{array}$ & $\begin{array}{l}\text { Persistent pain after } \\
\text { trauma }\end{array}$ & $\begin{array}{l}\text { Refractory } \\
\text { eczema }\end{array}$ & $\begin{array}{l}\text { Diabetes insipidus } \\
\text { Limp }\end{array}$ \\
\hline Symptom's duration & $1 / 2$ month & 1 month & 3.5 months & 6 months \\
\hline Imaging findings & Lytic lesion (Brain MRI) & $\begin{array}{l}\text { Lytic lesion (Pelvic } \\
\text { and lower limb CT) }\end{array}$ & $(-)$ & $\begin{array}{l}\text { Ectopic neurohypophysis, } \\
\text { thickened pituitary stalk, } \\
\text { loss of 'bright spot' } \\
\text { (Brain MRI) Lytic lesion } \\
\text { (Lower limb CT) }\end{array}$ \\
\hline Diagnosis (LCH III) & $\begin{array}{l}\text { Multisystem, Group 2-low risk } \\
\text { group/Group 3-localized special } \\
\text { site involvement }\end{array}$ & $\begin{array}{l}\text { Single system/Unifocal, } \\
\text { Group 2-low risk group }\end{array}$ & $\begin{array}{l}\text { Unifocal, } \\
\text { Group 2-low } \\
\text { risk group }\end{array}$ & $\begin{array}{l}\text { Multisystem, } \\
\text { Group 3-localized special } \\
\text { site involvement }\end{array}$ \\
\hline
\end{tabular}

MRI, magnetic resonance imaging; CT, computed tomography; LCH, Langerhans' cell histiocytosis.
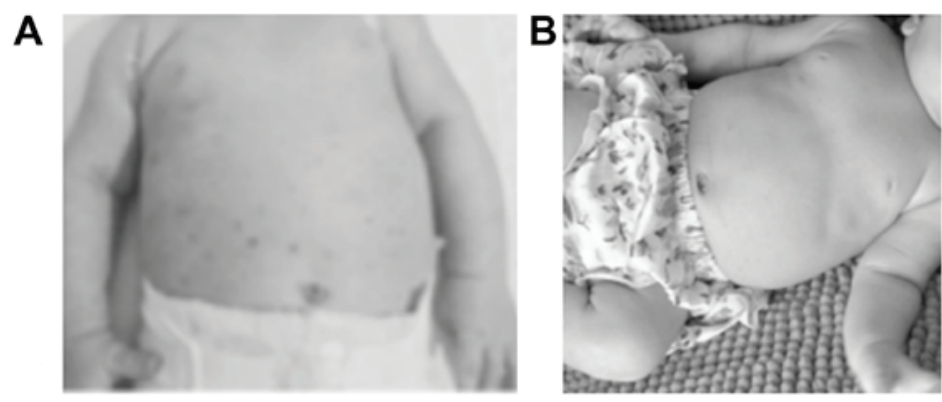

Figure 1. A 5-month old female LCH patient with persistent rash on the trunk since birth, (A) before and (B) after the first cycle of chemotherapy (prednisolone + vinblastine).

since birth (Fig. 1A). She was treated with intravenous ampicillin/sulbactam with prompt improvement. A skin biopsy of the trunkal rash was scheduled and the patient was discharged but returned three days later with recurrence of the inflammation in the left orbit. A plain film and MRI of the head revealed a lytic lesion in the frontal bone (Fig. 2A).

Patient no. 2. A 7-year-old boy with a history of Wolf-Parkinson-White syndrome presented with localized pain on the left hip with concomitant limp during the last month. The pain started after an injury while playing. A plain film of the hip at the time of the injury was normal. However, due to symptom persistence, imaging studies were performed (pelvic MRI and CT scan) that demonstrated a lytic lesion of the left iliac bone (Fig. 2B).

Patient no. 3. A 4-month old, otherwise healthy female infant was referred for a persistent circular, eczematous, perianal skin lesion approximately $5 \mathrm{~cm}$ in diameter. The lesion was initially treated with a local corticosteroid and antibiotic cream for a month without improvement. Because of the persistence of the lesion and of the non-typical location a biopsy was performed (Fig. 2C).
Patient no. 4. A 4.5 year-old boy with a known history of diabetes insipidus (DI) under hormone replacement treatment for the past two years was admitted for investigation of a limp and left lower limb pain. The pain had progressed over the past few weeks and was worse at night. At the time of DI diagnosis a brain MRI had showed an ectopic posterior pituitary gland. A plain film of the left lower limb revealed a $6 \mathrm{~mm}$ lytic lesion of the femur (Fig. 2D). A repeat brain MRI showed thickening of the pituitary stalk and loss of the 'bright spot' findings that are pathognomonic for pituitary gland $\mathrm{LCH}$, that preceded the bone involvement.

Management and outcome. $\mathrm{LCH}$ was confirmed in all patients with biopsy of the affected sites. All pathology specimens stained positive for CD1a, protein S-100 and CD207 (Langerin) confirming the diagnosis (Fig. 2C) (5). All the patients underwent a thorough hematological evaluation and further imaging (skeletal survey, abdominal ultrasound and CT or MRI scan) to exclude multifocal bone disease and risk organ involvement.

All patients were referred to a Pediatric Hematology-Oncology unit where they were managed according to the LCH III protocol after risk stratification (Table I) (6). Patient 4 had the femur lesion surgically resected before 

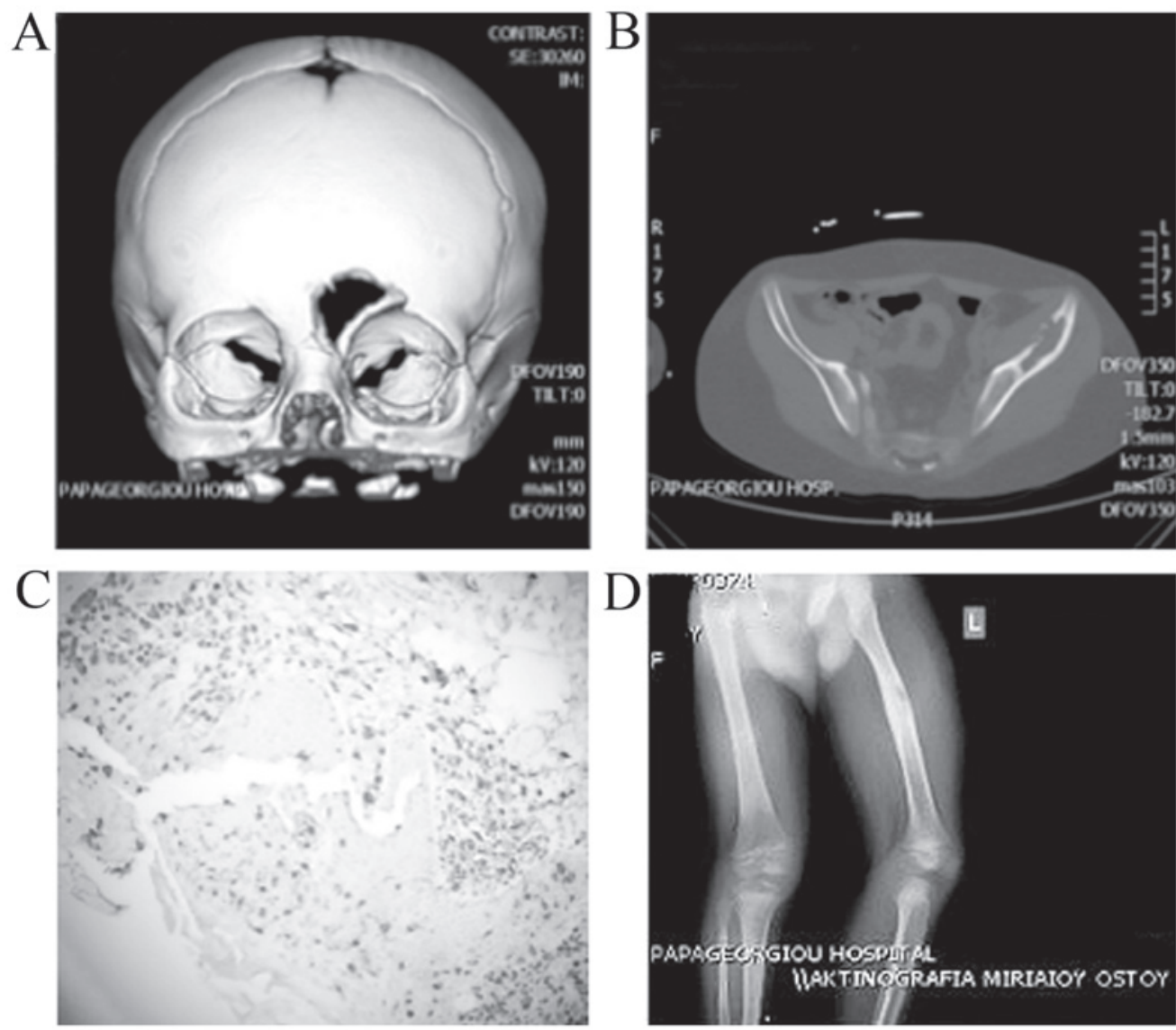

Figure 2. Initial imaging/pathology findings of all patients. (A) Patient no. 1: 3D-CT scan of the skull illustrating lytic lesion of the frontal bone. (B) Patient no. 2: CT scan of the pelvis illustrating lytic lesion of the left iliac bone. (C) Patient no. 3: Skin biopsy sample positive staining for protein S-100 (x200). (D) Patient no. 4: Plain film of the femur imaging lytic lesion of the left femur.

chemotherapy. All patients received induction treatment with IV vinblastine weekly and oral prednisolone daily for 6 weeks, followed by maintenance treatment for 6 months (IV vinblastine and 5 day pulses of oral prednisolone every 3 weeks). They all demonstrated a good response except patient 1 who had an immediate skin disease response (Fig. 1B), but quick recurrence of the lytic lesion at the same site while on treatment. A surgical excision of the patient's left orbital mass was performed and maintenance treatment was further continued for 12 months in total. Two months after the end of treatment, a routine imaging unveiled multiple new lytic lesions of the skull. A water deprivation test performed because of polyuria-polydipsia confirmed DI as a result of pituitary gland involvement. The patient received 3 cycles of cytarabine and cladribine (2-CDA) as second line therapy for persistent/relapsed disease and maintenance treatment (with mercaptopurine and methotrexate) for 12 months and is now in remission.

\section{Discussion}

The clinical presentation of $\mathrm{LCH}$ is heterogeneous as practically every organ or system may be affected. The disease is divided into single-system (uni- or multi-focal) or multi-system. Depending on the organs involved patients are divided as high-risk (lungs, liver, spleen, bone marrow) or as low-risk (skin, bones, lymph nodes, gastrointestinal tract) that can be either unifocal or multifocal. There is significant difference in mortality rates in the two risk groups. In agreement with the literature in our case series the organs most frequently affected were the skeleton (80\%), the skin (33\%), and the pituitary gland (25\%) (3).

Bone involvement may present as a painful bone lesion (patients nos. 2 and 3) or as a painless skull lytic lesion (patient no. 1). The bones most frequently affected are the skull, femur, ribs, humerus and the vertebrae. A skeletal survey is necessary to reveal asymptomatic sites (3). Lesions of the orbital, temporal, mastoid, sphenoid, zygomatic and ethmoid bones, as well as of the maxilla, sinuses and the anterior or middle cranial fossa are considered 'CNS-risk' lesions (patient no. 1) (3).

Diabetes insipidus (DI) is the most frequent type of CNS involvement and may precede or follow other manifestations (patient nos. 4 and 1, respectively). $\mathrm{LCH}$ is the most common cause of isolated DI and of a thickened pituitary stalk in brain MRI (7). Treatment should be initiated even without biopsy of the lesion, provided a germ cell tumor and a lymphoma have been excluded (7). Lacking specific imaging criteria, other MRI lesions resembling LCH that involve the skull need to be confirmed with biopsy in order to differentiate from other malignancies as meningioma, rhabdomyosarcoma and Ewing's sarcoma (8).

The incidence of the disease during early infancy is estimated to be 1-2/1.000.000, and the predominant initial symptom 
is a skin rash on the scalp or body, ranging from red or necrotic papules to hypopigmented macules or persistent 'cradle cap'. Underdiagnosis is usual when $\mathrm{LCH}$ manifests as a skin rash during early infancy (patients nos. 1 and 3, Fig. 1) because of the difficulty to differentiate it from benign skin conditions like eczema or bacterial infections (9). Although isolated cutaneous LCH may be self-limited it is essential for primary health care providers to be aware of the disorder and closely follow-up their patients because it may progress to multisystem disease (40\% of cases) (10), like patient no. 1. Among infants $\mathrm{LCH}$ is not only rarer but also carries a worse prognosis in comparison to older children, with a mortality rate reaching $50 \%(9,10)$.

The overall survival of low-risk LCH in children is estimated to be $99 \%$, but for high-risk LCH is around $80 \%$ with high possibility of relapse (11). The LCH-IV is an international collaborative treatment protocol that is expected to be completed by 2018 . Its main objectives are to reduce mortality and reactivation rates by intensification and prolongation of treatment especially in multisystem LCH and to devise strategies to avoid permanent consequences in treated patients (12).

BRAF is a kinase in the MAPK pathway playing a central role in cell growth. The BRAF-V600E mutation induces activation of the RAS/RAF/MAPK/ERK pathway. The discovery of recurrent BRAF-V600E and MAP2K1 mutations in LCH patients has revolutionized our understanding of the biology of the disease and has offered significant alternatives for its management. Therefore, despite ongoing considerations regarding safety and toxicity especially in childhood, agents such as vemurafenib, dabrafenib and trametinib have been recently introduced in the management of persistent and refractory $\mathrm{LCH}$ cases that harbor the mutations and have induced prolonged remissions (7).

Despite the advancements in our understanding of the disease's etiology and natural history and the novel therapeutic approaches for $\mathrm{LCH}$, there are pitfalls that may delay the diagnosis from three months to several years $(11,13)$, especially when the initial presentation is a common and non-specific symptom (patients nos. 2 and 3). Pediatricians, pediatric oncologists and other specialists treating children (family physicians, dermatologists, orthopedic surgeons, otorhinolaryngologists and dentists) should be familiar with the multiple faces of $\mathrm{LCH}$ in order to achieve timely diagnosis and to ensure appropriate treatment and optimal outcome.

\section{References}

1. Badalian-Very G, Vergilio JA, Fleming M and Rollins BJ: Pathogenesis of Langerhans cell histiocytosis. Annu Rev Pathol 8: 1-20, 2013.

2. Chakraborty R, Hampton OA, Shen X, Simko SJ, Shih A, Abhyankar H, Lim KP, Covington KR, Trevino L, Dewal N, et al: Mutually exclusive recurrent somatic mutations in MAP2K1 and BRAF support a central role for ERK activation in LCH pathogenesis. Blood 124: 3007-3015, 2014.

3. Haupt R, Minkov M, Astigarraga I, SchäferE, Nanduri V,Jubran R, Egeler RM, Janka G, Micic D, Rodriguez-Galindo C, et al: Langerhans cell histiocytosis ( $\mathrm{LCH})$ : Guidelines for diagnosis, clinical work-up and treatment for patients till the age of 18 years. Pediatr Blood Cancer 60: 175-184, 2013

4. Stålemark H, Laurencikas E, Karis J, Gavhed D, Fadeel B and Henter JI: Incidence of Langerhans cell histiocytosis in children: A population-based study. Pediatr Blood Cancer 51: 76-81, 2008.

5. Drutz JE: Histiocytosis. Pediatr Rev 32: 218-219, 2011.

6. Gadner H, Minkov M, Grois N, Pötschger U, Thiem E, Aricò M, Astigarraga I, Braier J, Donadieu J, Henter JI, et al: Therapy prolongation improves outcome in multisystem Langerhans cell histiocytosis. Blood 121: 5006-5014, 2013.

7. Allen CE, Ladisch S and McClain KL: How I treat Langerhans cell histiocytosis. Blood 126: 26-35, 2015.

8. Liang C, Liang Q, Du C, Zhang X and Guo S: Langerhans' cell histiocytosis of the temporal fossa: A case report. Oncol Lett 11: 2625-2628, 2016

9. Minkov M, Prosch H, Steiner M, Grois N, Pötschger U, Kaatsch P, Janka-Schaub G and Gadner H: Langerhans cell histiocytosis in neonates. Pediatr Blood Cancer 45: 802-807, 2005.

10. Lau L, Krafchik B, Trebo MM and Weitzman S: Cutaneous Langerhans cell histiocytosis in children under one year. Pediatr Blood Cancer 46: 66-71, 2006.

11. Grana N: Langerhans cell histiocytosis. Cancer Contr 21: 328-334, 2014

12. The Histiocyte society: LCH-IV International Collaborative Treatment Protocol for Langerhans Cell Histiocytosis. http://www.bspho.be/wp-content/uploads/LCH-IV-protocol-amend ed-version-Nov.-2015v1.3.pdf. Accessed January 8, 2017.

13. Abla O, Egeler RM and Weitzman S: Langerhans cell histiocytosis: Current concepts and treatments. Cancer Treat Rev 36: 354-359, 2010. 